\title{
Bioactivity of Echium Amoenum: A Mini Review
}

\author{
Jiri Patocka ${ }^{1,2 *}$ and Zdenka Navratilova ${ }^{3}$ \\ ${ }^{1}$ Department of Radiology, Czech Republic \\ ${ }^{2}$ Department of Biomedical, Czech Republic \\ ${ }^{3}$ Department of Botany, Czech Republic
}

*Corresponding author: Jiri Patocka, Department of Radiology, Toxicology and Civil Protection, University of South Bohemia in Ceske Budejovice, Czech Republic

\begin{tabular}{l} 
ARTICLE INFO \\
\hline Received: 幽 July 22, 2019 \\
Published: 幽 August 02, 2019 \\
\hline Citation: Jiri Patocka, Zdenka Navra- \\
tilova. Bioactivity of Echium Amoenum: \\
A Mini Review. Biomed J Sci \& Tech Res \\
20(2)-2019. BJSTR. MS.ID.003429.
\end{tabular}

\begin{abstract}
This paper deals with Echium amoenum, which is one of the most important medicinal plants in Iranian traditional medicine. The flowers of this plant have been used as antioxidant with anti-inflammatory and analgesic, anxiolytic, and sedative effects in folk medicine. In recent years, the importance of oxidative stress in the pathophysiology of many human disorders has been confirmed, and it is highly recommended to use this plant as a food supplement.
\end{abstract}

Keywords: Echium Amoenum; Traditional Medicine; Pharmacology

\section{Introduction}

Echium amoenum is a perennial herb native to the narrow zone Iran and the Caucasus known as „Iranian borage “. It is one of the most important medicinal herbs in traditional Iranian medicine, for infectious diseases, flu and as an anti-febrile. It grows from up to 2200 meters above sea level and it is used not only in folk medicine but also in the kitchen. This plant has a variety of effects, of which the most valuable are anti-inflammatory and analgesic effects. Also, antibacterial, antioxidant, and antiviral properties of borage have been shown in different articles [1] and recent phytochemical studies of E. amoenum showed various substances with neuroprotective effect [2]. Clinical studies on E. amoenum showed effectiveness in depression and anxiety disorders [3].

\section{Ethnobotanics}

Echium amoenum Fisch. \& CA Mey that is a member of Boraginaceae family [4] is a large $(60-100 \mathrm{~cm})$ herb growing in Northern parts of Iran and in the Mediterranean region of Europe (Figure 1). The flowers are bright blue and star-shaped, and the fruit consists of four brownish nutlets. This hairy plant is known as Borage and its flowers and the leaves have antibacterial effects [5]. It is also used in treatment of stress and depression [6]. The genus Echium has 4 species. However, only two of them - Echium vulgare and Echium amoenum - have been used in traditional medicine [7-9]. E. amoenum is one of the most important medicinal plants in Iranian traditional medicine, and its tea is one of the most commonly used herbal drugs. All parts of the plant, including stems, leaves and flowers have pharmaceutical uses [10]. E. amoenum is widely used as a sedative and mood enhancer. It is also used to treat cough, sore throat and pneumonia [2].

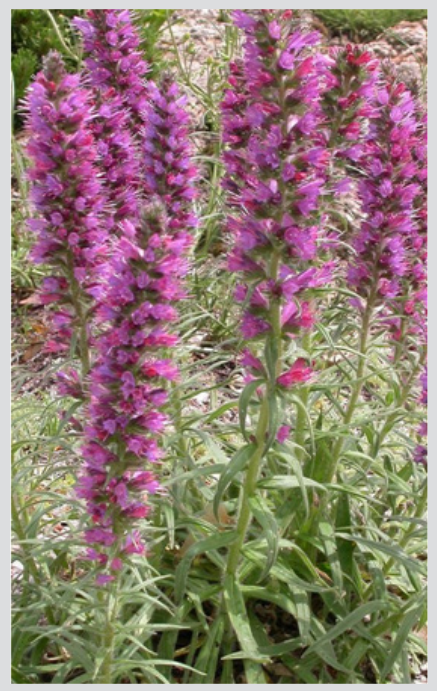

Figure 1: Flowering Iranian borage, Echium amoenum Fisch. \& CA Mey. 


\section{Pharmacology}

Flowers, stems, roots and leaves from the E. amoenum are used for medicinal purposes in traditional medicine. It represents an interesting source of various pharmacological activities [2]. Many biologically active substances were isolated from E. amoenum. These are mainlypolypenols with rosmarinic acid as the main ingredient [1] anthocyanidine, flavonoids, sterols, saponins, unsaturated terpenoids and unsaturated fatty acids [11,12] and trace amount of pyrrolizidine alkaloids [13]. The presence of these hepatotoxic alkaloids may be a problem, although it is not a reason to ban this popular herbal medicine. Nevertheless, further investigations including in vivo toxicological studies are required to confirm these points.

\section{Antioxidant Activity}

Antioxidant properties of the decoction of the flowers of $E$. amoenum was described by Ranjbar et al. Antioxidative stress potential of this plant may be due to its bioactive antioxidant components, mainly polyfenols as rosmarinic acid and flavonoids [14,11].

\section{Antibacterial Activity}

Because microorganisms become more and more resistant to antibiotic compounds, herbal antimicrobial drugs are an interesting source of new active ingredients. The study of Sabaeifard (2015) shows that the Echium amoenum aqueous extract has remarkable antimicrobial activity against Staphylococcus aureus, Escherichia coli, and Pseudomonas aeruginosa. In vitro aqueous extract of E. amoenum from dried flowers also showed concentrationdependent antibacterial activity against Staphylococcus aureus [5]. The traditional use of Iranian borage flowers for infectious diseases and for the control of fever seems justified.

\section{Antiviral Activity}

The aqueous extract of E. amoenum in concentration of 50$1000 \mu \mathrm{g} / \mathrm{ml}$ for 7 days is effective against herpes simplex virus type I [15]. This extract also showed concentration-dependent antiviral activity against free bacteriophage 3C, specific host of Staphylococcus aureus [16]. Antiviral activity of the extract is heat resistant and it can be rosmarinic acid which was found in this plant [17] and has antimicrobial, antiviral, and anti-inflammatory effects.

\section{Anti-Inflammatory and Immunomodulatory Activities}

E. amoenum has significant anti-inflammatory and immunomodulatory effects, including lymphocyte activation inhibitory effects, cellular and humoral suppression, and induces apoptosis [18]. Hexane extract of E. amoenum could modulate the inflammatory mode of the macrophages by inhibition in iNOS and COX2 enzymes and decreases IL-1 $\beta$, IL-6, and TNF- $\alpha$ cytokine levels [19].

\section{Neuroprotective Activity}

The neuroprotective effects of E. amoenum, including analgesic [20] anti-ischemic [11] and anxiolytic effects [21] have been shown in several animal models. Its extract shows protective effect against scopolamine-induced impairment [22]. Cyanidine-3-glucoside, which is the most important anthocyanin in the plant, has protective effects against brain damage and apoptosis caused by brain ischemia [23]. According to the articles mentioned above, it seems that E. amoenum may be effective against cognitive impairments caused by neurodegenerative diseases. Recent studies have suggested that the aqueous extract of E. amoenum is effective in treating patients with mild to moderate depression as well as obsessive-compulsive disorder [24] and generalized anxiety disorder [25].

On the rat model of Alzheimer's disease with destructed nucleus basalis Maynert (NBM) by oxidative stress was proved that that the treatment of animals with plant extract inhibited the acetylcholinesterase enzyme and improved the ability of spatial learning in the Morris water maze test. Given the pathophysiological and molecular similarities between the AD and NBM lesion models, E. amoenum could be used as a therapeutic adjuvant in patients suffering from Alzheimer's disease or similar cognitive disorders [26].

\section{Can Be E. Amoenum a Functional Food?}

Most medicinal plants exhibit specific therapeutic effects without having a nutritional role in the human diet. But this is not the case of E. amoenum. This plant is not only medicinal because it contains a number of beneficial substances but is also a nutrient plant [14]. However, the use of a plant as a functional food is complicated because its range is quite limited and is bound to a particular geographical area [27-31].

\section{Conclusion}

Echium amoenum is a perennial herb and it is one of the important remedies used in traditional Iranian medicine. The plant contains a number of bioactive substances. The plant has a number of pharmacological effects: antioxidant, antibacterial, antiviral, antiinflammatory and immunomodulatory, but also neuroprotective. As it also has a nutritional value, it is possible to use borage as a functional food.

\section{Conflict of interest}

The authors declare that there is no conflict of interest with regard to the topic, creation and publication of this article, and no pharmaceutical company has supported the creation or publication of the article.

\section{Acknowledgment}

This work was supported from Institutional Support for a longterm conceptual project of the University Hospital Hradec Králové, Czech Republic.

\section{References}

1. Ranjbar A, Khorami S, Safarabadi M, Shahmoradi A, Malekirad AA, et al. (2006) Antioxidant Activity of Iranian Echium amoenum Fisch \& C.A. Mey Flower Decoction in Humans: A cross-sectional Before/After Clinical Trial. Evid Based Complement Alternat Med 3(4): 469-473.

2. Behnammanesh G, Khalilpour S, Abdul Majid A, Abdul Majid A (2015) Pharmacological Actions and Potential Neuroprotective Effects of Rhus 
coriaria L. and Echium amoenum L.: A Brief Review. ebmedCentral pharmacology 6(11): WMC005008.

3. Azizi H, Ghafari S, Ghods R, Shojaii A, Salmanian M, et al. (2018) A review study on pharmacological activities, chemical constituents, and traditional uses of Echium amoenum. Phcog Rev 12(24): 208-213.

4. Zargari A (1989) Medicinal plants $4^{\text {th }}$ (Edn.), University Press, Tehran, Iran, pp. 510-539.

5. Abolhassani M (2004) Antibacterial effect of borage (Echium amoenum) on Staphylococcus aureus. Braz J Infect Dis 8: 382-385.

6. Sarris J, McIntyre E, Camfield DA (2013) Plant-based medicines for anxiety disorders, part 2: a review of clinical studies with supporting preclinical evidence. CNS Drugs 27(4): 301-319.

7. Ghassemi N, Sajjadi E, Ghannadi A, Shams-Ardakani M, Mehrabani M (2003) Volatile constituents of a medicinal plant of Iran, Echium amoenum Fisch. and CA Mey. Daru 11: 32-33.

8. Fisch A, Mey CA (2005) Main phenolic compound of petals of Echium amoenum Fisch and C.A. Mey., a famous medicinal plant of Iran. Daru- J Faculty Pharmacy 13(2): 65-69.

9. Uysal H, Kizilet H, Ayar A, Taheri A (2012) The use of endemic Iranian plant, Echium amoenum, against the ethyl methanesulfonate and the recovery of mutagenic effects. Tox Ind Health 31(1): 44-51.

10. Bargard NS, Assadi SM, Amini H, Saiiah M, Akhondzadeh S, et al. (2004) Efficacy of aqueous extract of Echium amoenum $L$. in the treatment of mild to moderate major depressive disorder: A randomized double blind clinical trial. J Med Plants 3(10): 61-68.

11. Safaeian L, Haghjoo Javanmard S, Ghanadian M, Seifabadi S (2015) Cytoprotective and antioxidant effects of Echium amoenum anthocyaninrich extract in human endothelial cells (HUVECs). Avicenna J Phytomed 5(2): 157-166.

12. Erdemoglua N, Kusmenoglua S, Vura M (2004) Gamma-linolenic acid content and fatty acid composition of Boraginaceae seed oils. Eur J Lipid Sci Technol 106(3): 160-164.

13. Mehrabani M, Ghannadi A, Sajjadi E, Ghassemi N, Shams-Ardakani M (2006) Toxic pyrrolizidine alkaloids of Echium Fisch. \& Mey. Daru J Pharm Sci 14(3): 122-127.

14. Adel Pilerood S, Prakash J (2014) Evaluation of nutritional composition and antioxidant activity of Borage (Echium amoenum) and Valerian (Valerian officinalis). J Food Sci Technol51(5): 845-854.

15. Farahani M(2013) Antiviral effect Assay of Aqueous Extract of Echium Amoenum-L Against HSV-1. ZJRMS 15 (8): 46-48

16. Abolhassani M (2010) Antiviral activity of borage (Echium amoenum). Arch Med Sci: AMS 6(3): 366-369.

17. Mehrabani M, Ghassemi N, Ghannadi ESA, Shams-Ardakani M (2005) Main phenolic compound of petals of Echium amoenum Fisch and CA

ISSN: 2574-1241

DOI: 10.26717/BJSTR.2019.20.003429

Jiri Patocka. Biomed J Sci \& Tech Res

This work is licensed under Creative

Commons Attribution 4.0 License

Submission Link: https://biomedres.us/submit-manuscript.php
Mey, a famous medicinal plant of Iran. DARU J Pharmaceut Sci 13(2): 65-69.

18. Amirghofran Z, Azadbakht M, Keshavarzi F (2000) E. amoenum stimulate of lymphocyte proliferation and inhibit of humoral antibody synthesis. Iranian J Med Sci 25: 119-124.

19. Naseri N, Kalantar K, Amirghofran Z (2018) Anti-inflammatory activity of Echium amoenum extract on macrophages mediated by inhibition of inflammatory mediators and cytokines expression. Res Pharm Sci 13(1): $73-81$

20. Heidari MR, Azad EM, Mehrabani M (2006) Evaluation of the analgesic effect of Echium amoenum Fisch \& CA Mey. extract in mice: possible mechanism involved. J Ethnopharmacol 103(3): 345-349.

21. Rabbani M, Sajjadi SE, Vaseghi G, Jafarian A (2004) Anxiolytic effects of Echium amoenum on the elevated plus-maze model of anxiety in mice. Fitoterapia 75(5): 457-464.

22. Rabiei Z, Setorki M (2018) Effect of hydroalcoholic Echium amoenum extract on scopolamine-induced learning and memory impairment in rats. Pharm Biol 56 (1): 672-677.

23. Miraj S, Kiani S (2016) A review study of therapeutic effects of Iranian borage (Echium amoenum Fisch). Der Pharmacia Lettre 8(6): 102-109.

24. Assadi SM, Amini H, Saiiah M, Akhondzadeh S, Kamalinejad M (2004) Efficacy of aqueous extract of Echium amoenum $L$. in the treatment of mild to moderate major depressive disorder: A randomized double blind clinical trial. J Med Plants 2(10): 61-68.

25. Sayyah M, Saayah M, Kamali-nejad A (2006) Preliminarry rnadomized double blind clinical trial on the efficacy of of aqueous extrakt of Echium amoenum in the treatment of mild to moderate major depression. Progr Neuro-Psychopharmacol Biol Psych 30(1): 166-169.

26. Sadeghi L, Yousefi Babadi V, Tanwir F (2018) Improving effects of Echium amoenum aqueous extract on rat model of Alzheimer's disease. J Integr Neurosci 17(3-4): 661-669.

27. Amirghofran Z (2010) Medicinal plants as immunosuppressive agents in traditional Iranian medicine. Iran J Immunol 7(2): 65-73.

28. Rabiei Z, Setorki M (2018) Effect of hydroalcoholic Echium amoenum extract on scopolamine-induced learning and memory impairment in rats. Pharm Biol 56 (1): 672-677.

29. Sabaeifard P (2015) Antibacterial aktivity of Echium amoenum aqueous and ethanolic extracts.Third International Student Biotechnology Congress.

30. (2013) Erratum In: CNS Drugs 27(8): 675.

31. Shafaghi B, Naderi N, Tahmasb L, Kamelinejad M (2002) Anxiolytic effect of Echium amoenum L. in mice. Iran J Pharm Res 1: 37-41.

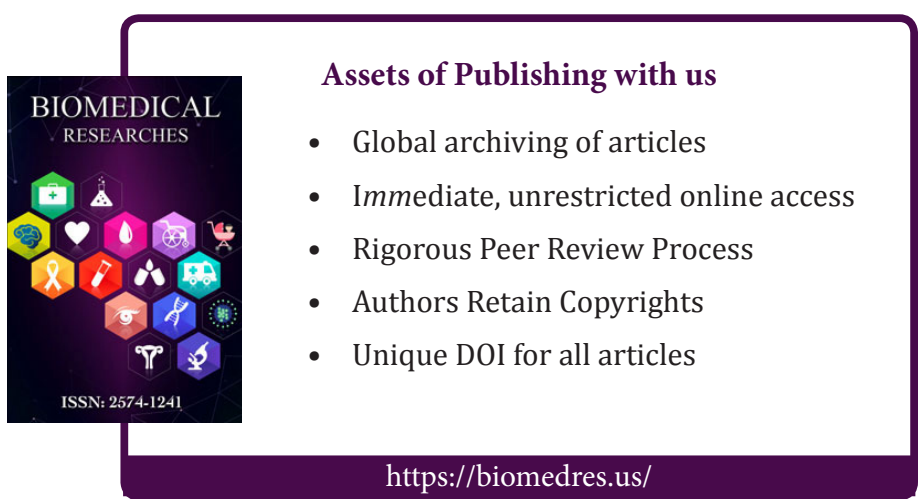

